In any case this line, and indeed any other which might be devised, can be true only as an average. The pressures in the vascular system of the body change continually under vasomotor influence. Contraction of arterioles lowers the pressure in the corresponding capillaries. Hence, if the pressure in a given capillary area is one-fifth of the initial pressure under ordinary conditions, it will be less than one-fifth when the arterioles feeding that area contract, and more than one-fifth when they dilate.

It is evident that the problems of blood pressure cannot be fully solved by considering, however carefully, the physical principles which are involved. The data at our disposal are insufficient. Yet these principles must be constantly borne in mind when we attempt to appraise the results arrived at in other ways.

REFERENCES.

I. Proceedings of the Royal Society of Medicine, Vol. VI, No. 3, p. 31.

. Nicholls, W.-- Journal of Physiology, Vol. XX, 1896, p. 43.

Vierordt, H. " "Daten und Tabellen," I906, p. I79.

. Starling.- " Elements of Human Physiology," 8th edition, p. 204.

(To be continued.)

\title{
A CONTRIBUTION TO THE PATHOLOGY OF CHOROIDAL MELANOMATA.
}

\author{
BY \\ R. Foster MoOre, F.R.C.S. \\ ASSISTANT SURGEON, ROYAL LONDON OPHTHALMIC HOSPITAL.
}

MELanomata of the choroid are of uncommon occurrence, and usually discovered by accident during routine ophthalmoscopic examination.

It is therefore only by some fortuitous chance that a specimen, which has been examined ophthalmoscopically during life, is obtained for microscopic examination.

In Volume XIX, Part iii, of the Royal London Ophthalmic Hospital (Moorfields) Reports were published four cases of this condition which I had examined clinically during life.

All four cases were discovered by accident, and none of them had given rise to symptoms.

A coloured drawing, by A. W. Head, of one of them is given in the Reports, and excellently depicts the ophthalmoscopic characters of these growths.

In one of the cases I was able, owing to the death of the patient from myasthenia gravis, to obtain the specimen, and microphotographs of both bleached and unbleached sections of this tumour are included. 
It is pointed out in that paper that the ophthalmoscopic appearances of this last specimen differed in two particulars from the appearances of the three remaining cases, and I expressed some doubt as to whether this case was properly classed as a melanoma, and whether it might not in the course of time have manifested malignant characters had the patient lived.

A very complete post-mortem examination was made by Dr. T. H. G. Shore, but no evidence of dissemination was found, although specially looked for; nor did sections of the growth show any unequivocal signs of malignancy.

The two particulars in which this specimen differed from the other three when seen with the ophthalmoscope were: (1) a number of vesicle-like spots were present scattered over the area of the growth, but nowhere else in the fundus; (2) the edge lacked the slightly feathered appearance which was present in the other cases.

A consideration of cases published by Nettleship and de Schweinitz and Shumway lends rather strong support to Nettleship's suggestion, namely, that the presence of stippling or irregular pigmentation over the area of the tumour may indicate that it is actively growing.

I have thought the present case worth publishing because I was able to examine it ophthalmoscopically on three occasions during life, and it was in every essential precisely similar to the first three of the former cases, and to the coloured plate which is included with them, i.e., it had what I take to be the typical ophthalmoscopic appearances of a choroidal melanoma, without the modifications which were present in the other specimens which I obtained.

The following is an abstract from my former paper of the ophthalmoscopic characters of these growths:

"In size they varied from about one-half the area of the disc to about four times its area."

"They were roughly circular or oval in outline."

"The edges were everywhere quite definite without being quite hard and sharp; there was no shading off into the surrounding fundus, nor was there any light fringe or evidence of pigmentary disturbance at the edge."

"They were of quite homogeneous appearance, and the choroidal pattern, although plainly seen around, was not seen over the area of the growths."

"In colour they were exactly that of blue ointment, differing from each other only in their density."

"All were single and close to the papilla."

"They were all discovered by chance: none of them having given rise to symptoms."

"During the time the patients were under observation (6 weeks, 
$5 \frac{1}{2}$ months, $5 \frac{1}{2}$ months, 10 days) there was no change in the appearances."

"There was no abnormal pigmentation of the eyes discoverable, on external examination."

As already stated, the foregoing description is accurate in every essential for the present specimen.

There was no irregularity of pigmentation discernible, nor stippling or other change over the area of the tumour, the edges of which were slightly feathered and not hard or sharp.

The patient, a man, aged 53, was under the care of Mr. W. H. H. Jessop, to whom I am indebted for permission to publish the case.

The man attended on account of failing sight, and was found to have well-marked papillœdema. A diagnosis of cerebral neoplasm was made, and a decompression operation was performed by Mr. L. B. Rawling.

Previous to the operation, the tumour in the choroid was somewhat obscured, owing to the extension of the oedema of the papilla into the retina, where it overlaid the growth.

With the relief of the intra-cranial pressure, the odema subsided considerably; and on two subsequent examinations, a clear view was obtained.

The patient died two weeks after the operation, and a post-mortem examination was made by Mr. A. L. Moreton, of whose full notes the following is a short abstract :

J. C. Post-mortem examination, Dec. 20th, 1915.

"A tumour was found lying in relation with the sylvian point on the left side.

It was oval in outline and measured three inches by two.

It was perfectly circumscribed, had an imperfect capsule, and was adherent to the overlying meninges.

It compressed and displaced the neighbouring portions of the frontal, temporo-sphenoidal, and parietal lobes.

It could be shelled out from the depression which it had made in the brain."

\section{Description of Tumour.}

I removed the eyeball entire. It was embedded in celloidin, and sections were planned to include the optic disc (showing papillœdema) and the growth (Fig. 1).

Some sections were immediately stained with hæmatoxylin and eosin (Fig. 2), and others were so stained after bleaching with permanganate of potash and oxalic acid.

The tumour was about one disc's breadth distant from the edge of the papilla (Fig. 1). 
It was roughly circular in outline, and conformed in every particular to the general description already given.

Its extreme breadth was $1.9 \mathrm{~mm}$., and its thickness $0.4 \mathrm{~mm}$.

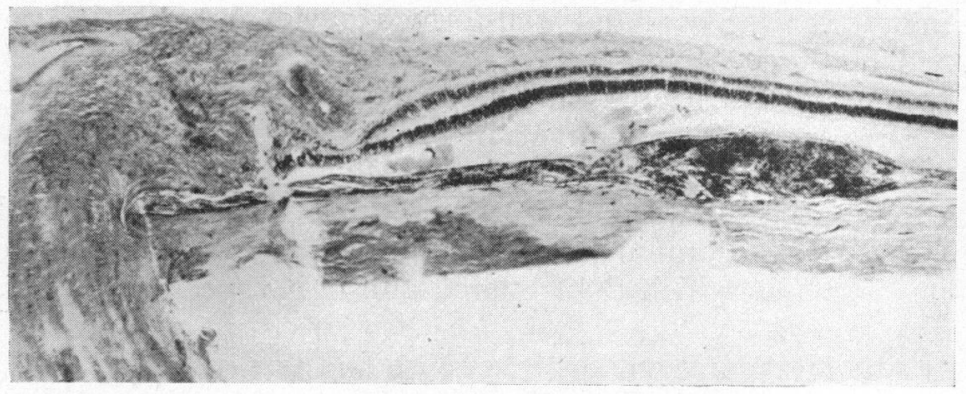

FIG. 1.

Shows the general shape and position of the tumour and of a portion of the optic disc, which is in a condition of papilloedema.

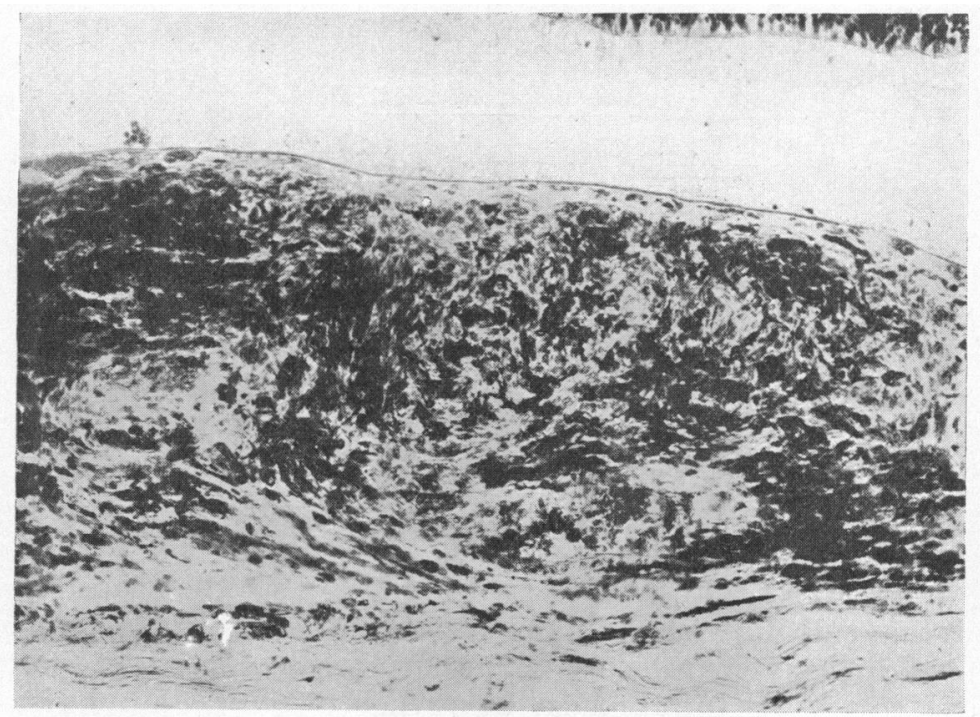

FIG. 2.

Shows the arrangement of the cells of the growth and the somewhat irregular distribution of the pigment.

The nature of the cells is not well shown.

The chorio-capillaris and the sclerotic are uninvolved.

It appeared to be formed in the more superficial layers of the choroid.

The overlying retina, pigment epithelium, and chorio-capillaris showed no change. 
The sclerotic was not involved by the growth (Fig. 1).

The mass of the tumour was composed of very broadly spindleshaped cells which showed a tendency in places to be arranged in coarse bundles (Fig. 2).

The nuclei were oval and well-formed; evidence of active mitosis was not observed.

Pigment was scattered throughout the growth in a somewhat uneven manner. The bulk of it was intra-cellular. I could not, however, be sure that none was extra-cellular.

In some places it was contained in globular cells; in other places it appeared to be contained in the long processes of branching cells.

The points in which this differed from the specimen previously reported were :-

(1) The pigmentation was less dense and less uniform.

(2) The arrangement of the cells was not quite so regular, and the large spheroidal cells, crowded with pigment, were much less conspicuous in this than in the former case.

There can, I think, be no doubt that this is an example of a melanoma of the choroid, benign in character, and probably congenital in origin.

\section{THE REMOVAL OF FOREIGN BODIES BY MEANS OF A GIANT MAGNET.}

BY

G. H. Pooley, F.R.C.S. SHEFFIELD.

In my earlier work with the giant magnet, I followed the technique of Haab. As my own experience has led me to modify very considerably the views I then held, and as I am convinced that I now get better results since the change in technique, I venture briefly to outline my views and my practice, giving my reasons.

Haab assumes that most foreign bodies are spindle-shaped (melon seed) and smooth. My experience is that they are more frequently irregularly triangular flakes with sharp angles, and that they are much inclined to turn broadside on when they meet any resistance. Most of the foreign bodies I have to deal with are from steel works, and are fresh from the fire and nearly aseptic.

When the foreign bodies are situated in or behind the lens my rules are :

1. Do not make any attempts to remove the foreign body before its situation has been carefully localized. Three or four days' wait makes no difference to the result. I have removed some foreign bodies after twenty years, others after ten years; and many in the second and third week, and later, with excellent results. 